Disponível em

http://www.anpad.org.br/rac

RAC, Curitiba, v. 13, Edição Especial, art. 2, p. 19-38, Junho 2009

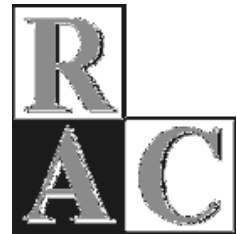

\title{
O Processo de Certificação Socioambiental das Empresas: o Estudo de Caso do Certificado 'Empresa Cidadã'
}

\section{The Socio-environmental Certification Process in Companies: the Case of 'Citizen Company' Certification}

André Luiz Bufoni * Doutorando em Planejamento Ambiental pela COPPE/UFRJ. Professor Assistente da UFRJ, Rio de Janeiro/RJ, Brasil.

Natiara Penalva Muniz Mestre em Ciências Contábeis pela UFRJ. Professora da UNIFESO, Rio de Janeiro/RJ, Brasil.

Aracéli Cristina de Sousa Ferreira Doutora em Controladoria e Contabilidade pela USP. Professora da UFRJ, Rio de Janeiro/RJ, Brasil.

Copyright (C 2009 RAC. Todos os direitos, inclusive de tradução, são reservados. É permitido citar parte de artigos sem autorização prévia desde que seja identificada a fonte. 


\section{RESUMO}

Este artigo trata de Contabilidade Social Corporativa, em uma de suas formas mais conhecidas, preferidas e utilizadas: o Balanço Social. O objetivo deste estudo é a análise da eficácia do processo de certificação do Empresa Cidadã, promovida pelo Conselho Regional de Contabilidade do Rio de Janeiro [CRC/RJ], que teve por objetivo "elevar a qualidade e a transparência dos relatórios sociais publicados e incentivar a realização de balanços sociais pelas organizações". Efetuou-se ainda uma análise qualitativa dos dados apresentados para certificação. Este trabalho se utiliza então do estudo de caso simples como metodologia, tendo a certificação como caso e o processo como unidade em análise. Esta pesquisa conclui que, apesar da melhoria contínua, da consolidação do processo, da sofisticação e da tecnicidade e abrangência, o processo ainda se encontra distante de alcançar os objetivos de influenciar as decisões dos gestores e modificar o comportamento das instituições sobre investimentos desta natureza. A análise dos dados é dificultada pela inconsistência, heterogeneidade e posicionamento das informações apresentadas, enquanto o processo em si se revela excessivamente quantitativo, apresentando ainda o problema da não publicidade dos critérios e julgamentos efetuados na análise dos dados.

Palavras-chave: balanço social; contabilidade social corporativa; responsabilidade social.

\section{ABSTRACT}

This study is about one of the most known, used and preferable means of Corporate Social Accounting: the Social Report. The core objective of this study is the analysis of the efficacy of the Citizen Company certification process. This process was introduced by the professional accounting regulatory agency CRC/RJ and analyzed by the Federal University of Rio de Janeiro for the purpose of "improving quality and transparency of corporate socio-environmental", one of the few that deals with matters such as financial reporting and the importance of audit attestation. A qualitative analysis of the data submitted for certification was also carried out. Thus, the methodology used in this paper is the simple case study. The conclusions reveal that, unlike Conclusions reveal that, in opposition to process continued improvement, the inconsistence, heterogeneity and placement of information difficult the data analysis, while certification seems to be hard quantitative and give no publicity to how it judges the reported information.

Key words: social report; corporate social accounting; social responsibility. 


\section{INTRODUÇÃO}

Este artigo trata de Corporate Social Accounting [CSA] ou Contabilidade Social Corporativa ${ }^{(1)}$, ou do direito dos diversos grupos de interesse da sociedade (constituencies) à informação concernente as atividades corporativas que afetam (ou podem afetar) seus próprios interesses (Roth, 1982), em uma de suas formas mais conhecidas: o Balanço Social. Ao contrário do que se pensa, o assunto não é novo. Apenas o interesse de acadêmicos e profissionais encontrava-se adormecido desde os anos 70 época do surgimento do conceito de desenvolvimento sustentável e responsabilidade social reaparecendo na década passada (Alexander, 1974; Cauthorn, 1977; O’Dwyer, 2001; Owen \& Swift, 2001; Taylor, 1976).

Na medida em que as questões sociais e ambientais são cada vez mais importantes para o sucesso dos negócios (Ellington, 1997 como citado em Owen \& Swift, 2001; O’Dwyer, 2001), a responsabilidade social corporativa deve expressar valores, condutas e procedimentos que induzam e estimulem o contínuo aperfeiçoamento dos processos empresariais, mas que também resultem em preservação e melhoria da qualidade de vida da sociedade do ponto de vista ético, social e ambiental (Tachizawa, 2002, p. 86). O Balanço Social é um desses instrumentos, adicionando transparências às ações das corporações.

De fato, a análise das 250 maiores empresas multinacionais publicadas na Revista Fortune, entre os anos de 1998 e 2001, revelou incrível aumento (50\%) das informações relacionadas ao desenvolvimento sustentável. Nessa amostra, estes tipos de relatórios costumam ser mais comuns entre as empresas do setor industrial e menos comuns entre os dos serviços financeiros, do comércio e das comunicações (Kolk, 2003), justamente as mais criticadas. Repetida a investigação, conforme a Corporate Responsibility Management (Anonymous, 2005), a nova pesquisa confirmou a tendência mundial de aumento. Tais resultados nas pesquisas têm incentivado que cada vez mais as organizações divulguem este tipo de informação.

Um dos mecanismos criados para dar visibilidade à conduta sociorresponsável e a incentivar a divulgação de informações socioambientais é a certificação. Não sendo regulamentada nem obrigatória, a divulgação de demonstrativos socioambientais pelas empresas brasileiras, a certificação configura-se como poderoso mecanismo de educação, de controle e de informação ao consumidor. A certificação é um dos instrumentos de autocontrole da gestão socioambiental privada, dentro das diretrizes de um desenvolvimento sustentável.

A importância do presente trabalho reside no fato de a certificação não ser apenas uma demonstração de atenção a um mais amplo grupo de interessados (stakeholders) que diminui o risco potencial do negócio, mas efetivamente uma maneira de adicionar valor ao negócio (Rosthorn, 2000), de legitimar condutas corporativas (Laufer, 2003); pela atenção que chama, a dimensão socioambiental é ferramenta indutora de aprendizado institucional (Gond \& Herrbach, 2006). A certificação traz diretrizes que, atentamente observadas, podem criar um capital reputacional. Descuidar-se de sua reputação pode limitar o desempenho financeiro da corporação (Miles \& Covin, 2000, p. 309).

As razões gerenciais para que as empresas participem do processo de certificação são (Humble, 1975 como citado em Kok, Wiele, McKenna, \& Brown, 2001): (1) como parte de um plano estratégico e operacional para rever as práticas existentes com relação à responsabilidade social interna e externa; (2) para determinar pontos fortes e fracos em estratégias e práticas; (3) com relação ao desenvolvimento de um plano de melhoria contínua; (4) para medir o progresso dos esforços para implementação da responsabilidade social na organização; (5) para obter a participação de pessoas que são capazes de contribuir para o desenvolvimento da responsabilidade social.

Este trabalho teve por objetivo principal a análise da eficácia do processo de certificação de Empresa Cidadã, promovida pelo Conselho Regional de Contabilidade do Rio de Janeiro [CRC/RJ] e analisada pela Faculdade de Administração e Ciências Contábeis da Universidade Federal do Rio de Janeiro. 
Essa certificação tem como objetivo "elevar a qualidade e a transparência dos relatórios sociais publicados e incentivar a realização de balanços sociais pelas organizações".

De posse de todas as informações, este trabalho também procurou, como objetivo secundário, avaliar a qualidade da certificação e analisar as informações oferecidas pelas empresas que participaram do processo.

\section{REVISÃO DA BIBLIOGRAFIA}

Algumas idéias têm sido usadas para advogar que as empresas têm a obrigação de medir e de divulgar o seu desempenho social (AICPA ${ }^{(2)}$ como citado em Roth, 1982); são elas: (1) de natureza econômica, que as atividades podem ser nocivas e suas conseqüências não estão computadas nos custos das empresas, causando a subavaliação de produtos e a inapropriada alocação de recursos econômicos $^{(3)}$; (2) mais filosófica, baseia-se na crença de que as empresas têm essa obrigação social, porque a sociedade lhes deu a permissão para operarem e; (3) a pragmática, que as empresas tomam inúmeras ações com conseqüências sociais e a sociedade deve ser capaz de julgar se essas ações são adequadas e apropriadas.

Uma parte da literatura indica que, a partir da concepção de novos modelos econômicos e conceitos como desenvolvimento sustentável e responsabilidade social, surgiram forças externas e internas, pressionando pela evidenciação de informações dos tipos ambiental e social.

As pressões externas por informações sociais podem vir de vários grupos (minorias, consumidores, ambientalistas, serviços comunitários), influenciando as formas de evidenciação, desde o relatório anual - preferido e eleito como mais confiável pela maioria dos respondentes - até rótulos e manuais de produtos. Mas, entre esses grupos, parece haver consenso de que a divulgação de tais informações ainda é insuficiente (81\%), bem como a regulamentação a respeito do assunto (David, 2003; Tilt, 1994). O ambiente tem trazido também muitas variáveis às pesquisas, como tamanho e origem das instituições, organização do mercado, nível de regulamentação, entre outras, tentando determinar as circunstâncias em que favorecem a sua apresentação (para uma revisão ver Adams, 2002; Gray, Kouhy, \& Lavers, 1995). Essa pressão é conhecida como Risco Reputacional (United Nations Conference on Trade and Development [UNCTAD], 2003).

As empresas percebem que estão sendo pressionadas principalmente pelo nível de exigência de mercados desenvolvidos no que concerne ao seu acesso àqueles mercados, seja por meio de certificação (enfoque institucional, informal, direto ou privado), seja por meio de normas emitidas por órgãos reguladores: ótica pública, indireta ou formal. Para Donaire (1999, p. 35 como citado em Lima \& Viegas, 2002), o social e o ambiental estão se tornando oportunidades para abrir mercados e prevenir-se contra restrições futuras ao acesso a mercados internacionais, pois estes demandarão informações financeiras completas (full disclosure) e de qualidade.

Mas não é só a pressão externa que influencia o nível de evidenciação. Genericamente, sabe-se que a evidenciação diminui a incerteza, o risco e, por conseqüiência, o custo do capital (Botosan \& Plumlee, 2002; Miller, 2001). Especificamente, pesquisas sobre a relação entre o nível de evidenciação social e o desempenho econômico das empresas indicam ainda que: (1) apesar de sua relação não ser direta e clara; (2) é possível afirmar que existe uma correlação negativa entre a evidenciação social e o risco sistêmico (BETA); e (3) que parece haver relação positiva entre a evidenciação social e o horizonte decisorial da gerência da empresa (Adams, 2002; Klassen \& McLaughlin, 1996).

É plausível afirmar então que a divulgação de informações sociais é gerencialmente desejável. Por exemplo, os negócios lucrariam mais com uma mais completa evidenciação do passivo ambiental, se eles levarem a um enfoque proativo que os protejam não só de um aumento dos custos na demora em 
identificar questões ambientais, mas também à redução imediata e, às vezes, dramática em seus custos de produção (Williams \& Phillips, 1994).

\section{Legitimidade da Contabilidade na Produção de Relatórios Sociais}

Desde há muito se sabe que o processo de produção de relatórios sociais passa primeiro pelo entendimento da administração sobre seu papel social específico e na necessidade da ampliação dos limites da contabilidade financeira para permitir a divulgação das informações sociais, já que a contabilidade financeira convencional não tem servido para medir o desempenho social das empresas (Taylor, 1976). Desde que os Princípios Contábeis Geralmente Aceitos [PCGA] não foram desenvolvidos para dados sociais, mas financeiros (Hendriksen \& Breda, 2001), os gerentes estão livres para escolher as formas de medição e apresentação que acreditarem ser mais apropriadas. Mas a literatura nos chama a atenção para o fato de que, uma vez tomada a decisão de divulgar a informação social, que isso deva ser feito da maneira mais completa e honesta possível, correndo o risco de não ser levada a sério (Roth, 1982). Boas intenções apenas não são suficientes para obter bons resultados (Taylor, 1976).

Estas dificuldades têm levado os profissionais e acadêmicos a questionar a legitimidade dos contadores em participar na produção de tais relatórios (O’Dwyer, 2001). Mas, dada a similaridade entre os relatórios financeiros e sociais, a contabilidade já tem uma estrutura desenvolvida para lhes dar suporte, o que torna o processo mais barato e mais fácil (Solomon, 2000, p. 51). Boschi (2003) encontrou a contabilidade como principal contribuinte, fornecendo as informações quantitativas, em $78 \%$ das observações de sua amostra. Eis um aspecto interessante que merece discussão mais profunda, mas que foge do escopo deste trabalho.

\section{Balanço Social no Brasil}

Estudos sobre Balanço Social desenvolvidos no Rio Grande do Sul (88), na Federação Brasileira de Associação de Bancos [FEBRABAN] (50), Santa Catarina (8), Guia da Boa Cidadania da Revista Exame (22) e no Ibase (127), mostram que em geral a evidenciação destes demonstrativos, apesar de difundida de forma crescente, se apresenta ainda bastante deficiente; obedecendo a modelos diferenciados; sem a apresentação de inúmeros valores para os indicadores (cerca de $31 \%$ ), que são muito variados, e; não indo além de dois períodos (Boschi, 2003; Carpes, 2004; Carvalho \& Siqueira, 2005; Costa, 2002; David, 2003; Pinto, 2003; Ribeiro \& Santos, 2002).

No Brasil, a regulamentação sobre Balanço Social foi abordada em Carvalho e Siqueira (2005), comparando as quatro vertentes definidas pelo Instituto de Pesquisas Contábeis, Atuarias e Financeiras $[\text { [FIPECAFI }]^{(4)}$ e resumida na Tabela 1 a seguir:

Tabela 1: Vertentes Definidas pela FIPECAFI

\begin{tabular}{|l|c|c|c|c|}
\hline \multirow{2}{*}{ Regulamentações } & \multicolumn{3}{|c|}{ Vertentes definidas pela FIPECAFI } \\
\cline { 2 - 5 } & DVA & $\begin{array}{c}\text { Balanço } \\
\text { Ambiental }\end{array}$ & $\begin{array}{c}\text { Balanço de } \\
\text { Recursos } \\
\text { Humanos }\end{array}$ & $\begin{array}{c}\text { Contribuições a } \\
\text { Sociedade em } \\
\text { Geral }\end{array}$ \\
\hline NBCT 15 & Sim & Não & Sim & Sim \\
\hline Projeto Lei 1305/03 & Não & Sim & Sim & Sim \\
\hline Projeto Lei 0032/99 & Não & Não & Sim & Sim \\
\hline Lei N 2.843/03-AM & Não & Não & Sim & Sim \\
\hline Lei N 7687/02-MT & Não & Não & Sim & Sim \\
\hline Lei N 11440/00-RS & Não & Não & Sim & Sim \\
\hline Lei N 9536/04- Londrina & Não & Não & Sim & Sim \\
\hline Lei N 7672/98 - Santo André & Não & Não & Sim & Sim \\
\hline Lei N 8118/98 - Porto Alegre & Não & Não & Sim & Sim \\
\hline
\end{tabular}

Fonte: Carvalho e Siqueira (2005, p. 6). 
Da Tabela 1 é possível concluir que dimensões do social, como a perspectiva ambiental, não foram ainda incorporadas pela legislação, enquanto a demonstração de valor adicionado [DVA] o foi apenas com a edição da Lei 11.638 no final de 2007. Outro ponto ainda pouco abordado pelas leis e normas brasileiras é sobre a necessidade de uma atestação externa destes demonstrativos, pois, como não há regulamentação dos órgãos oficiais, a qualidade da atestação de tais relatórios é também "horrivelmente pobre" (Gray, 2001, p. 13).

O marketing, proporcionado pelo balanço social, é aspecto de extrema relevância que pode seduzir os empresários a publicá-lo, por entenderem-no como novo instrumento de publicidade (Kroetz, 2000).

Outro aspecto interessante é que raramente pesquisas no exterior, ou no Brasil, fazem análises fundamentadas em dados dos demonstrativos sociais das empresas. A grande maioria se concentra (no Brasil todas as verificadas) em aspectos institucionais e na quantidade e tipo de dados fornecidos, sem em momento algum entrar no mérito dos números, estabelecer indicadores ou avaliar as ações sociais propriamente ditas (externas ou internas).

\section{Esforço de Padronização e o Papel da Certificação}

A certificação é um dos instrumentos de autocontrole da gestão socioambiental privada, dentro das diretrizes de um desenvolvimento sustentável. Veio substituir os antigos instrumentos de comando e controle públicos que tomaram vulto, por sua vez, junto com a emergência de questões relacionadas ao desemprego na Europa, e ao meio ambiente desde a Conferência das Nações Unidas em Estocolmo (1972). O quadro adaptado de Magrini (1999) resume o assunto:

Tabela 2: Instrumentos de Controle

\begin{tabular}{|c|c|c|c|}
\hline Objetivos & Atividades & Objetos & Produtos \\
\hline \multirow{3}{*}{ Econômicos } & Taxas & $\begin{array}{l}\text { Aplicação do Princípio } \\
\text { Poluidor Pagador }\end{array}$ & $\begin{array}{l}\text { Receita sobre o Direito } \\
\text { de Poluir }\end{array}$ \\
\hline & Subsídios e Incentivos & $\begin{array}{l}\text { Implantação de } \\
\text { Equipamentos e Sistemas } \\
\text { de Controle, adoção de } \\
\text { Tecnologias Limpas }\end{array}$ & $\begin{array}{l}\text { Melhoria de } \\
\text { desempenho }\end{array}$ \\
\hline & Certificados Negociáveis & $\begin{array}{l}\text { Comercialização do } \\
\text { Direito de Poluir }\end{array}$ & $\begin{array}{l}\text { Bolsa de Direitos de } \\
\text { Poluir }\end{array}$ \\
\hline \multirow{5}{*}{ Comando e Controle } & Cadastramento & $\begin{array}{l}\text { Atividades Poluidoras e } \\
\text { Prestadores de Serviços }\end{array}$ & Cadastros \\
\hline & Licenciamento & Projetos & $\begin{array}{l}\text { RIMA/EIA, Licença } \\
\text { Prévia, de Instalação e } \\
\text { Operação. }\end{array}$ \\
\hline & Fiscalização & $\begin{array}{l}\text { Verificação de } \\
\text { Conformidade com } \\
\text { Licenças e Legislação }\end{array}$ & \\
\hline & Análise de Risco & $\begin{array}{l}\text { Prevenção da Poluição } \\
\text { Acidental/Controle de } \\
\text { Cargas Perigosas }\end{array}$ & $\begin{array}{l}\text { Planos de Emergência, } \\
\text { Contingência e } \\
\text { Segurança }\end{array}$ \\
\hline & Credenciamento & $\begin{array}{l}\text { Agentes Privados de } \\
\text { Controle }\end{array}$ & Credencial \\
\hline
\end{tabular}


(conclusão)

Tabela 2: Instrumentos de Controle

\begin{tabular}{|l|l|l|l|}
\hline \multicolumn{1}{|c|}{ Objetivos } & \multicolumn{1}{|c|}{ Atividades } & \multicolumn{1}{c|}{ Objetos } & \multicolumn{1}{c|}{ Produtos } \\
\hline \multirow{2}{*}{ Autocontrole } & PROCON & $\begin{array}{l}\text { Verificação de } \\
\text { Conformidade }\end{array}$ & Relatórios Periódicos \\
\cline { 2 - 4 } & Manifesto & Auto-Licenciamento & Declaração \\
\cline { 2 - 5 } & Auditoria & $\begin{array}{l}\text { Verificação de } \\
\text { Conformidade }\end{array}$ & Relatório \\
\cline { 2 - 5 } & Certificação & $\begin{array}{l}\text { Sistemas de Gestão de } \\
\text { Processos, Auditoria, } \\
\text { Ciclos de Vida de } \\
\text { Produtos }\end{array}$ & Selos e Certificados \\
\hline
\end{tabular}

Fonte: adaptado de Magrini (1999, p. 17).

Para Carvalho e Siqueira (2005), os selos e certificados são uma forma de incentivo criado quando a regulamentação não institui a divulgação do balanço social como obrigatória. Segundo Kroetz (2000, p. 44):

os programas de certificação configuram-se em poderosos mecanismos de educação, de controle e de informação ao consumidor, que utiliza as forças indutoras da oferta para exigir produtos mais saudáveis e ecologicamente corretos. Cabendo à entidade que deseja permanecer no mercado e adaptar-se a nova realidade e tendências.

Em inúmeros países existem experiências bem sucedidas de certificação. Cada uma dessas certificações apresenta seus próprios modelos de planejamento, gestão, controle e evidenciação e em sua maioria formam padrões de relatórios seguidos pelas empresas. Alguns acreditam que há padrões que nem sequer chegam a formar relatórios, sendo apenas um conjunto de indicadores, tal a flexibilidade do que é possível incluir e retirar do modelo, como do Intergovernamental Working Group of Experts on International Standards and Reporting [ISAR] um dos programas do United Nations Conference on Trade and Development [UNCTAD] (Dias, 2006). Essa diversidade tem-se tornado antes problema que virtude (Clifford, 2005; Gray et al., 1995), já que exige maior empenho por parte das instituições para se adequar a diversos padrões. Apresentamos algumas dessas experiências nacionais e internacionais a seguir.

ISAR/UNCTAD. O ISAR é o Intergovernmental Working Group of Experts on International Standards of Accounting and Reporting, um dos programas do United Nations Conference on Trade and Development [UNCTAD] (2003). "O objetivo do ISAR é promover a transparência, confiabilidade e comparabilidade da contabilidade corporativa e das demonstrações, assim como melhorar a evidenciação na governança corporativa pelas empresas nos países em desenvolvimento e economias em transição". Por meio de uma iniciativa voluntária, foi emitida a referência Global Reporting Initiative [GRI] (http://www.globalreporting.org) contendo: (1) princípios de evidenciação a ser seguidos pelos elaboradores; (2) especificação do conteúdo; e (3) sugestão de 50 principais indicadores, incluindo ambientais, sociais e econômicos; (4) e mais 47 indicadores adicionais. Os indicadores principais são considerados relevantes para a maior parte das empresas e dos stakeholders. Sua utilização tem sido crescente.

AA1000. Um esforço de ordenação e padronização conhecido é o AA1000 do Reino Unido, cujo objetivo é "melhorar a transparência e o desempenho das organizações, aumentando a qualidade de seus relatórios sociais" (O'Dwyer, 2001, p. 31). O AA1000, lançado pelo Institute of Social and Ethical Accountability (ISEA, 1999), é padrão voluntário para os processos de contabilização, auditoria e evidenciação ética e social. Para Gobbels e Jonker, (2003), o processo de certificação do AA1000 pode levar a empresa a melhor definição de objetivos e metas, e a melhor avaliação do progresso feito com relação a essas metas. 
SA8000. Pouco conhecido no Brasil, o Social Accountability [SA] 8000 é um conjunto de padrões de trabalho desenvolvido pelo Social Accountability International, com apoio das Nações Unidas e várias ONG's e está baseado no Conventions of the International Labour Organization (ILO, 1998) e na Declaração dos Direitos Humanos das Nações Unidas (Gobbels \& Jonker, 2003 como citado em Miles \& Munilla, 2004; Leipziger, 2001). A Comissão Européia explicitamente indica a SA8000 como padrão internacional (European Commission, 2001b). O formato proposto oferece enfoque mais holístico do desenvolvimento sustentável, com diretivas que consistem em (1) selagem social de produtos; (2) padrões de evidenciação social corporativos; (3) condições de trabalho; (4) questões de direitos humanos; (5) desempenho ambiental; e (6) aplicação da regulação, além da cadeia de valor (European Commission, 2001a). De maneira similar à ISO 14000, a SA8000 é certificada por uma terceira parte.

Certificados ISSO. Ainda dentro da filosofia de adesão voluntária é que encontramos os padrões ISO. A ABNT lançou, em dezembro de 2004, a ABNT NBR 16001 - Responsabilidade Social Sistema da Gestão - Requisitos. Segundo a Consultoria JP Verithas (2006),

a ABNT NBR 16.001 objetiva prover às organizações os elementos de um sistema da gestão da responsabilidade social eficaz, passível de integração com outros requisitos de gestão, de forma a auxiliá-las a alcançar seus objetivos relacionados com os aspectos ambientais, econômicos e sociais. Visa permitir à organização formular e implementar uma política e objetivos que levem em conta os requisitos legais e outros, seus compromissos éticos e sua preocupação com a promoção da cidadania, transparência das suas atividades; e promoção do desenvolvimento sustentável.

Um objetivo bastante ambicioso. Em si, a ISO 16.001 não estabelece nenhum padrão de apresentação de demonstrações e sim, como todas as outras, o desenvolvimento de um Sistema de Gestão Socioambiental e a implementação de uma filosofia de melhoria contínua, com a observância de legislação vigente no país. Ainda assim, a ISO 16.001 muda o enfoque para as pessoas; "a preocupação baseia-se no ser humano, nas pessoas, na sociedade, é o investimento na qualidade de vida das pessoas e não mais apenas nos procedimentos organizacionais e em seus produtos" (Boger, 2006).

Modelo IBASE. O Instituto Brasileiro de Análises Sociais e Econômicas [IBASE] é uma instituição de utilidade pública federal, sem fins lucrativos, sem vinculação religiosa e politicopartidária. Sua missão é a construção da democracia, combatendo desigualdades e estimulando a participação cidadã. Teve como fundador o sociólogo Betinho, que dizia que "realizar o Balanço Social significa uma grande contribuição para consolidação de uma sociedade verdadeiramente democrática" (IBASE, 2009). Esta iniciativa começou em 1997, com apoio das lideranças empresariais. Em 1998, para estimular a participação de maior número de corporações, o IBASE lançou o Selo Balanço Social IBASE/Betinho. O selo é conferido anualmente a todas as empresas que publicam o balanço social no modelo sugerido pelo IBASE, dentro da metodologia e dos critérios propostos. Por meio deste selo as empresas podem mostrar, em seus anúncios, embalagens, balanço social, sites e campanhas publicitárias, que investem em educação, saúde, cultura, esportes e meio ambiente. Os critérios que regem 0 modelo podem ser encontrados em http://www.balancosocial.org.br/media/criterios_selo_2005.pdf. A certificação é sem dúvida a experiência de maior sucesso no Brasil, com cerca de 60 empresas certificadas anualmente, mas com mais de 200 participantes no mesmo período.

\section{Os Objetivos e a EFICÁCIA dAs CerTIFICAÇÕEs}

Como visto anteriormente, as certificações foram criadas como mecanismos de autorregulação de mercado, principalmente onde a estrutura institucional é deficiente (Carvalho \& Siqueira, 2005), e seu objetivo (impacto esperado) dentro das organizações é estimular a ocupação sistemática e constante da 
administração com os sistemas de gestão de processos que sejam sustentáveis, de auditoria ambiental e com os ciclos de vida de seus produtos (Magrini, 1999).

O poder de determinada certificação está associado a sua adoção pelos mercados consumidores, principalmente àqueles localizados nos países economicamente desenvolvidos, como barreira à entrada dos produtos; e ainda como condição ao acesso a mercados financeiros com mais abundantes e baratas formas de financiamento (Donaire, 1999, p. 35 como citado em Lima \& Viegas, 2002).

Assim, a possibilidade de melhor desempenho econômico seria o mais importante motivador de ações neste campo, desempenho esperado que nem sempre é observado. A busca por uma relação entre desempenho econômico e desempenho socioambiental sempre foi o objetivo frequentado das pesquisas (Dentchev, 2004; Laan \& Witteloostuijn, 2007).

Muito embora a teoria sobre ética nos negócios espere que as empresas façam a coisa certa para o bem da sociedade, seja ela uma disposição do gestor em ser ético, ou dever-se apenas ao oportunismo de uma situação favorável (Alzola, 2008), a teoria econômica admite que a responsabilidade social primeiro se constitua em ferramenta para a consecução dos objetivos econômicos, concedendo vantagem tática no mercado, adquirindo o capital reputacional e a fidelidade por gratidão do consumidor (Detomasi, 2008; Giacalone, Paul, \& Jurkiewicz, 2005).

Apesar de a mudança para um comportamento organizacional sustentável ser a filosofia por detrás da certificação, muitas empresas apenas dão tratamento cosmético ao problema social ocasionado por sua própria atividade, por meio da produção de extensos relatórios que possuem importantes vieses (favoráveis) na escolha das informações a serem divulgadas (Bufoni \& Ferreira, 2006). Para Cerin (2002, p. 309), "gastando menos em um impressionante relatório ambiental, as grandes empresas podem, ao mesmo tempo, ganhar legitimidade ambiental, e economizar milhões, não tendo de atender ao verdadeiro problema de melhorar suas performances ambientais". A atitude é conhecida internacionalmente como greenwashing e deve ser uma das que o processo de certificação deveria ocupar-se em inibir, dificultar ou atrasar a consecução dos objetivos da certificação.

\section{METODOLOGIA}

Por se tratar de inquirição empírica que investiga um fenômeno contemporâneo dentro de seu contexto real, optamos pelo estudo de caso simples, como estratégia para a presente pesquisa (Yin, 1994). Estudos de casos permitem entender por que e como, ou entender a complexidade e a natureza dos processos que estão ocorrendo (Benbasat, Goldstein, \& Mead, 1987).

Nosso caso é a Certificação Empresa Cidadã, promovida pelo CRC-RJ. O nosso objeto de análise é o processo de elaboração e de análise para a certificação em questão. Os estudos de casos são conhecidos pelas múltiplas formas de coleta de dados (Yin, 1994). Tivemos acesso a documentações e relatórios dos anos analisados.

Não é possível ainda nenhuma inferência para a população brasileira de empresas; uma vez que o processo é voluntário, apenas se candidataram empresas que apresentaram balanços ou relatórios sociais e que acreditavam ter chances de ser certificadas (as melhores e mais bem informadas). Além dessas, pequenas e médias empresas também enviaram questionários para avaliação do Laboratório de Modelagem de Sistemas Contábeis da Faculdade de Administração e Ciências Contábeis da UFRJ [LMSC/UFRJ] e foram avaliadas pelos mesmos critérios das grandes empresas. Entre o ano de 2005 e os anteriores foram encontradas algumas pequenas diferenças, como mudança de valor para percentual e a exclusão ou inclusão de alguns poucos indicadores. Mudanças que tiveram de ser resolvidas com a aplicação de uma tabela de equivalência. 
A ausência da apresentação sistemática e da homogeneidade nos índices tem tanto dificultado a utilização de métodos positivistas nas pesquisas, como trazido dúvidas até mesmo da legitimidade do assunto como área da contabilidade (Gray et al., 1995). Por isso e porque as chances de encontrar resultados significativos em pequenas amostras são poucas (Baroudi \& Orlikowsky, 1989; Stevens, 1980), optamos pela análise qualitativa dos relatórios.

\section{ESTUDO DE CASO - O EMPRESA CIDADÃ}

O Certificado Empresa Cidadã é uma iniciativa do Conselho Regional de Contabilidade do Estado do Rio de Janeiro, como forma de incentivo à divulgação de informações socioambientais ou, como na página do CRC/RJ (2007), "elevar a qualidade e a transparência dos relatórios sociais publicados e incentivar a realização de balanços sociais pelas organizações"

Seguiu-se que a iniciativa encontrou acolhimento em algumas entidades que vieram participar do processo como parceiros. São elas, a Federação das Indústrias do Estado do Rio de Janeiro [FIRJAN], a Federação do Comércio do Estado do Estado do Rio de Janeiro [FECOMÉRCIO] e a Faculdade de Administração e Ciências Contábeis da Universidade Federal do Rio de Janeiro [FACC/UFRJ].

O Certificado Empresa Cidadã, que em 2007 estava na sua quinta edição, teve como candidatos o número de organizações abaixo:

Tabela 3: Empresa Cidadã Ano a Ano

\begin{tabular}{|l|l|l|l|l|l|}
\hline Edições Anteriores & 2003 & 2004 & 2005 & 2006 & 2007 \\
\hline Grandes Empresas & 17 & 19 & 31 & 38 & 48 \\
\hline Micro e Pequenas Empresas & - & 28 & 41 & - & 4 \\
\hline Empresas Analisadas & 17 & 47 & 72 & 38 & 52 \\
\hline Empresas Inabilitadas & N.D & N.D & N.D & N.D & $(5)$ \\
\hline Empresas Habilitadas & 17 & 47 & 72 & 38 & 47 \\
\hline Empresas Certificadas & 8 & 12 & 18 & 22 & 32 \\
\hline Menção Honrosa & 1 & 3 & 9 & - & - \\
\hline N.D - Não divulgado. & & & &
\end{tabular}

Fonte: elaboração própria.

As empresas participaram voluntariamente, encaminhando as informações necessárias para a análise do Conselho. Algumas exigências eram feitas para participação no processo como regularidade econômico-financeira e jurídico-fiscal. De acordo com o artigo $2^{\circ}$ do regulamento, somente foram analisados os Balanços Sociais ou Relatórios Sociais que contenham, também, a assinatura de contabilista em situação regular com o CRC.

A análise então foi feita por uma comissão especialmente nomeada para essa finalidade e contou com o apoio técnico do LMSC da FACC/UFRJ que, por sua vez, se baseia no regulamento aprovado pelo Conselho. A regulamentação teve como base primária para a avaliação o modelo IBASE de divulgação de informações sociais. As empresas que apresentaram outro tipo de demonstração foram avaliadas segundo aquele modelo. O Modelo do IBASE foi escolhido pela divulgação e abrangência que tem alcançado no Brasil, entre os anos de 2001 e 2005, com quase 1.000 demonstrações. Em 
média, anualmente, são apresentadas 180 demonstrações. A amostra de 40 empresas nessa população é, então, significativa.

Na edição de 2007 as empresas foram separadas em três grupos para certificação: (1) empresas de capital aberto; (2) empresas de capital fechado; (3) pequenas e médias empresas. Apesar disso, não foi modificada a modelagem e o peso dos indicadores para a avaliação tanto das empresas abertas quanto fechadas, sendo a diferenciação efetuada por concessão às empresas fechadas, dos pontos referentes aos itens que não são obrigatórios (grupo transparência e auditoria), que totalizavam 31 pontos.

Nas edições de 2004 e 2005 da certificação foram aplicados, pela FECOMÉRCIO, questionários envolvendo questões sociais para pequenas e médias empresas, tendo retornado 28 e 41 questionários respectivamente. Não foi possível operacionalizar a aplicação do mesmo questionário para as edições dos anos de 2006 e 2007. Em 2007, 4 empresas apresentaram demonstrativos socioambientais, mas não atenderam aos requisitos mínimos para participação. Nos anos em que apresentaram questionários, as pequenas e médias empresas foram avaliadas pelos mesmos critérios das grandes empresas. $\mathrm{O}$ procedimento foi considerado deficiente e, segundo informado, planeja-se alterá-lo para futuras edições. As pontuações em 2005 foram as seguintes:

Figura 1: Pontuação Pequenas e Médias Empresas em 2005

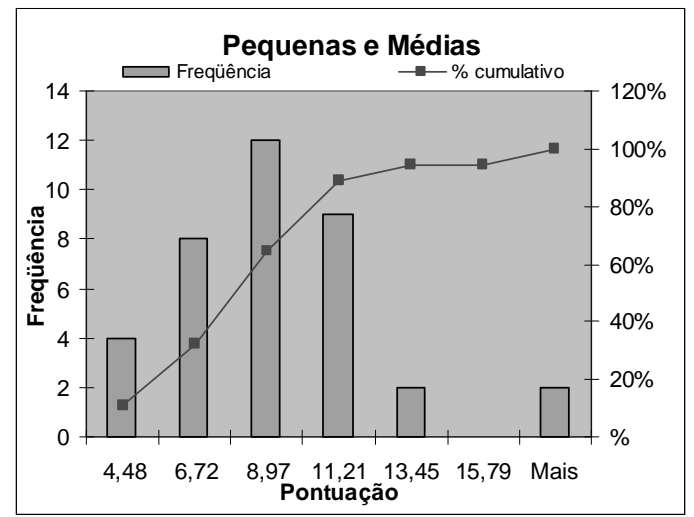

$\mathrm{O}$ peso de cada indicador foi estipulado de forma consensual entre os analistas e a comissão especial, e aprovado pela plenária do CRC-RJ. Os critérios de análise em 2006 foram os seguintes: (1) verificou-se a existência dos vários itens que compõem o modelo; (2) analisavam-se as variações favoráveis ou desfavoráveis em cada índice do modelo, quando fosse aplicável. Os índices foram divididos em 3 categorias: Informações Contábeis e Sociais (74 pontos); Informações do Corpo Funcional (20 pontos); e Informações Relevantes do Exercício de Cidadania (6 pontos). Os indicadores de Informações Contábeis e Sociais, por sua vez, eram divididos em 6 categorias: Indicadores Sociais Externos (10 pontos); Indicadores de Recursos Humanos (24 pontos); Transparência (25 pontos); Auditoria (3) e Indicadores de Investimento (10 pontos); e de Investimentos Sociais e Ambientais (2). No ano de 2007, não se alteraram as proporções.

A certificação acontecia quando os concorrentes alcançavam metade dos pontos possíveis (50). É possível notar um aumento considerável nos critérios exigidos ano a ano. Para 2006, o diferencial do Certificado Empresa Cidadã está na determinação dos pesos e na análise que é dada às informações contábeis, como a DVA; em exigir balanço social assinado por contabilista em situação regular; e na questão da auditoria das demonstrações socioambientais.

Somente a partir de 2007, o Conselho Regional de Contabilidade decidiu dar divulgação dos principais pontos em que foram encontradas não-conformidades com as avaliações efetuadas pelo grupo de analistas, tendo o cuidado de não divulgar as informações individualmente. Conforme se explicita a seguir. 


\section{Sobre a Análise das Informações Apresentadas para Certificação}

Nesta parte apresentamos fatos relevantes e dificuldades dignas de nota, encontradas no processo de análise das demonstrações apresentadas para certificação em 2005, 2006 e 2007 pelo CRC-RJ. Foi observado, em mais de um caso, que alguns valores de investimento de um período (e.g 2003) divergiam na demonstração subsequente. Tal inconsistência levou os analistas à adoção do último valor divulgado, acreditando tratar-se de retificações.

Apesar de que a maioria das empresas apresentar seus Balanços ou Relatórios Sociais e as Demonstrações de Valor Adicionado [DVA], não parece haver consenso onde lhes dar publicidade. Algumas empresas fizeram tal publicação de seus balanços sociais anexa às demonstrações contábeis e outras em relatórios sociais à parte. Da maneira análoga, a DVA foi apresentada anexa às demonstrações contábeis e outras como anexo ao próprio Balanço Social.

Cabe ressaltar que em todos os grupos havia o indicador OUTROS que o grupo de trabalho não pode analisar, pois as empresas não fizeram nenhuma menção a que tipos de investimentos seriam esses. Como o crescimento dessa alínea tem sido significativo, talvez seja o caso de desmembrá-los.

As demais partes das avaliações apresentaram os seguintes pontos.

Informações Contábeis e Sociais. A maioria das empresas evidenciou os passivos trabalhistas e os passivos fiscais nas demonstrações contábeis. A grande maioria das empresas não evidenciou os passivos ambientais. Em 2006, apenas 2 empresas fizeram tal evidenciação, e 6 em 2007. São elas, a Companhia Vale do Rio Doce e a Petróleo Brasileiro S/A [PETROBRAS], CSN, Invepar, Furnas e Eletrobrás. Quanto aos investimentos de 2006, apenas 3 empresas publicaram investimentos em tecnologia. Este número aumentou para $10 \mathrm{em}$ 2007. A maioria das empresas não publicou investimentos em pesquisa e desenvolvimento e investimentos em plantas e instalações, mas publicou investimento em meio ambiente, o que é bem mais amplo do que o investimento somente na recuperação ambiental. Foram considerados, mesmo assim, por pura impossibilidade de segregá-los.

Como dito anteriormente, a certificação passou, em 2006, a pontuar as empresas que apresentassem atestação externa de suas demonstrações, o que, apesar de apenas 4 empresas o terem feito, representa incentivo à produção de relatórios mais confiáveis. No ano seguinte 11 empresas apresentaram parecer ou carta sobre as demonstrações.

Recursos Humanos. Os investimentos em recursos humanos novamente receberam especial atenção dos responsáveis pela elaboração das demonstrações sociais. No ano de 2007, houve incremento na qualidade das informações apresentadas. Quando as empresas se propuseram a apresentar os indicadores referentes a esse grupo, o fizeram de maneira bem completa. Das empresas analisadas 9 obtiveram pontuação igual a 0 ; isto equivale a dizer que quase $20 \%$ das entidades não apresentaram nenhuma informação sobre os investimentos realizados para seus funcionários. Os investimentos em segurança e medicina do trabalho, encargos sociais, participação nos lucros, alimentação e previdência privada, como havia ocorrido em 2006, continuaram sendo divulgado pela maioria das empresas.

Indicadores de Atividades Sociais Externas. Estes indicadores estão diretamente relacionados aos investimentos que as entidades realizam na sociedade: 11 entidades não apresentaram nenhuma informação sobre esses investimentos e receberam nota zero. Pode-se destacar que 39 empresas analisadas divulgaram os investimentos em programas comunitários; em contrapartida, destacam-se os investimentos em creches, em que apenas duas empresas apresentaram tal informação. No ano de 2007, os itens relacionados aos investimentos na área de educação, culturas e outros foram encontrados na maioria das empresas analisadas, fato que já ocorreu em 2006. Mais uma vez o indicador OUTROS não pode ser analisado, pois as empresas não fazem nenhuma menção a que tipos de investimentos seriam esses.

Informações do Corpo Funcional. Estes indicadores serão analisados mais profundamente. A divulgação de determinados quesitos sobre o corpo funcional parece estar relacionada com o 
compromisso ético e social das empresas com a transparência. Eles mostram as políticas dos empregadores e apresentam um quadro geral que poderia levar a questionamentos (e.g. em pelo menos uma empresa o número de negros é menor que o de deficientes). Todas as empresas divulgaram o número total de empregados, com exceção de uma empresa. As empresas, em sua maioria, publicaram o número de empregados acima de 45 anos; o número de mulheres; o número de portadores de deficiências; o número de acidentes de trabalho ocorridos no exercício; e o número de mulheres em cargo de chefia. Pouco mais da metade das empresas (17 empresas) publicou em 2006 o número de excluídos que trabalham nelas. Vale ressaltar que, de acordo com os organismos internacionais (National Minority Supplier Development Council, 2005), excluídos correspondem a descendentes de africanos e povos indígenas. Nenhuma empresa publicou informação relativa ao número de funcionários com remuneração superior a dois salários mínimos, bem como nenhuma empresa publicou informação relativa a empregados com idade inferior a 23 anos. No ano de 2007, houve incremento na qualidade das informações apresentadas. Quando as empresas se propunham a apresentar os indicadores referentes a esse grupo, o fizeram de maneira bem completa.

Informações Relevantes do Exercício de Cidadania. Quanto ao código de ética, foi necessária uma busca mais ampla, porque, na maioria dos casos, esta informação não estava junto com as demonstrações socioambientais. As informações foram buscadas nos sites das empresas; em alguns casos, chegou-se a ligar para os setores de RH para a confirmação de sua existência. Em vista disso, metade das empresas não publicaram, (1) a existência de um código de ética; (2) se o código de ética era de conhecimento do corpo funcional; e (3) se era efetivamente cumprido. A maioria das empresas não publicou a existência de incentivo à pesquisa, ciência e tecnologia ou a existência de alguma política social de combate ao trabalho do menor. Os quadros abaixo resumem, ainda, as questões do indicador de participação dos empregados em programas voluntários e dos mesmos padrões éticos e de responsabilidade social e ambiental adotados pela empresa nos respectivos anos:

Tabela 4: Participação dos Empregados como Voluntários

\begin{tabular}{|c|c|c|}
\hline & 2006 & 2007 \\
\hline Incentivam & 14 & 14 \\
\hline Apóiam & 9 & 16 \\
\hline Não se envolvem & 1 & 2 \\
\hline Não publicaram & 7 & 20 \\
\hline
\end{tabular}

Tabela 5: Padrões Éticos dos Fornecedores

\begin{tabular}{|l|c|c|}
\hline & 2006 & 2007 \\
\hline Exigidos & 14 & 15 \\
\hline Sugeridos & 10 & 18 \\
\hline Considerados & 0 & 1 \\
\hline Não publicaram & 7 & 18 \\
\hline
\end{tabular}

\section{ANÁLISE DO CASO}

O programa Empresa Cidadã do Conselho Regional de Contabilidade do Rio de Janeiro, tendo dobrado de tamanho em apenas quatro edições da certificação, apresenta-se consolidado. O Empresa Cidadã ainda é um dos únicos que aborda aspectos contábeis das demonstrações, aponta explicitamente a necessidade de atestação dos demonstrativos socioambientais por auditores externos e exige a assinatura do contador.

O processo tem sofrido melhoria contínua, em tecnicidade e amplitude. Precisam ser aprimorados os métodos de avaliação de pequenas e médias empresas. A análise dos dados das empresas é dificultada 
pela heterogeneidade e a diversidade de posicionamento dos indicadores e das demonstrações. Há inconsistências nos valores de investimento divulgado em um ano e este mesmo investimento referente a esse ano, na demonstração subseqüente. Foi encontrada uma parte significativa do montante de investimentos que não pôde ser corretamente identificada, por estar aglomerada na alínea Outros Investimentos, presente em todos os grupos dos balanços sociais.

Foram observadas na última edição sofisticações, como categorização e agrupamento das empresas a serem analisadas em pelo menos abertas e fechadas e por tamanho. Espera-se ainda a adoção de instrumentos e análises mais adequadas às pequenas e médias empresas, e o tratamento específico no caso das empresas sem fins lucrativos.

Quanto aos objetivos e à eficácia do processo, objetivo deste trabalho, apesar da evolução notada, é possível verificar que a certificação em análise não se relaciona com a responsabilidade social, mas com a divulgação das informações socioambientais, consoante com o objetivo específico de "elevar a qualidade e a transparência dos relatórios sociais publicados e incentivar a realização de balanços sociais pelas organizações" (CRC/RJ, 2007). Em outras palavras, este objetivo não premia a atitude sociorresponsável e pode levar a mais investimentos na atividade-meio de divulgar o desempenho socioambiental (greenwashing).

O processo de aprendizagem institucional, que se inicia com a intuição, indo até a fase em que passa a constar das rotinas e controles (interpretação, integração e institucionalização) (Zietsma, Winn, Branzei, \& Vertinsky, 2002) não é estimulado pelo processo de certificação. Com isso a certificação não auxilia de maneira marginal, por exemplo, na gestão dos recursos destinados ao meio ambiente, ou se eles devem ser aplicados na melhoria ambiental dos produtos ou na melhoria ambiental dos processos Gilley, Worrell, Davidson e El-Jelly (2000, p. 1210).

O alvo primário da certificação então não expande os horizontes decisoriais para incorporar a dimensão ambiental (Klassen \& McLaughlin, 1996). A decisão ou não de participar do processo de certificação proposto não cria nenhuma expectativa de barreira a mercados desenvolvidos (Bufoni, Muniz, \& Ferreira, 2007), redução do custo do capital (Botosan \& Plumlee, 2002; Miller, 2001), ou de ser uma boa oportunidade de acesso a mercados internacionais (Donaire 1999, p. 35 como citado em Lima e Viegas, 2002).

Além disso, a metodologia escolhida para análise das informações é excessivamente quantitativa e objetiva, levando em consideração apenas a apresentação de indicadores e ao julgamento de seus valores representativos. Verificou-se que este tratamento dos dados parece estar relacionado ao modelo escolhido para servir de referência (IBASE).

Até a última edição, não era dada publicidade aos critérios de avaliação, o que tornava todo o processo ineficaz do ponto de vista da melhoria da qualidade e da transparência, uma vez que ele mesmo não deixava claros os critérios exigidos e julgamentos efetuados. Como resultado, as candidatas não sabiam como poderiam ou deveriam melhorar suas informações para serem certificadas.

\section{CONCLUSÕES}

Este artigo teve por objetivo a análise da eficácia do processo de certificação do Empresa Cidadã efetuado pelo Conselho Regional de Contabilidade do Rio de Janeiro que, por sua vez, tem por objetivo "elevar a qualidade e a transparência dos relatórios sociais publicados e incentivar a realização de balanços sociais pelas organizações" (CRC/RJ, 2007).

Apesar dos efeitos benéficos ocasionados à reputação das organizações pela obtenção do certificado objeto deste estudo, não encontramos evidências de que exista qualquer esforço ou aprendizado institucional, adequação de atividades e tentativa de melhoria contínua ou implementação de 
conceitos, políticas e processos socialmente responsáveis que sejam decorrentes da existência da certificação, pelos motivos que passaremos a expor mais adiante.

Do ponto de vista da existência de vários processos, a certificação pode até ser negativa, diante da indisponibilidade de uma informação mais acurada. Por exemplo, se existirem programas voluntários de desempenho ambiental com níveis diferentes de exigência, uma empresa proativa pode ser incapaz de se diferenciar das demais empresas de seu mercado (Darnall \& Carmin, 2005).

Do ponto de vista gerencial das operações, o impacto do processo é limitado à contribuição que faz no arcabouço de outras instituições mais fortes, como, por exemplo, as que limitam o acesso a mercados (ISO) e põe em evidência, de maneira mais abrangente, a imagem das instituições. Do ponto de vista do órgão regulador/certificador, o trabalho contribui na reflexão da aplicação de recursos (custos) em um processo e principalmente no conhecimento de sua contrapartida menos obvia: a parcela dos benefícios correspondentes.

Este trabalho traz, de maneira subliminar, a discussão sobre a dualidade paradoxal conhecida como greenwashing ou a aparência de responsabilidade socioambiental que, pelos objetivos do instrumento e pelos achados do presente estudo, parece ser mesmo incentivada. Entendendo-se que a certificação objeto da pesquisa não se ocupa em verificar a existência e a veracidade dos processos descritos nos relatórios das instituições.

Mesmo assim, a presente pesquisa conclui que, apesar da melhoria contínua, da consolidação do processo, da sofisticação e da tecnicidade e abrangência, o processo ainda encontra-se distante de alcançar os objetivos a que se propõe.

Os dados analisados apontam os seguintes fatores como responsáveis pelo enfraquecimento da eficácia.

1) Heterogeneidade dos indicadores e posicionamento nas diversas demonstrações, o que dificulta a localização das informações necessárias à certificação, fazendo com que informações relevantes sejam truncadas em meio às irrelevantes para o processo e aumentando o esforço de pesquisa.

2) Inconsistências dos valores apresentados, o que diminui a confiabilidade dos valores, mesmo os consistentes, que o poderiam ser no erro (neutralidade), não representarem fielmente os eventos econômicos (fidelidade) ou ainda não poderem ser comprovados (verificabilidade).

3) Fraco poder de influenciação, o que não estabelece barreiras a mercados desenvolvidos ou oportunidades de acesso a novos mercados, não possui impacto significativo ou serve de referência ao custo do capital. É relativamente novo, pouco conhecido e pouco abrangente.

4) Ausência de critérios qualitativos e a existência de um formato rígido: o problema leva, por exemplo, a uma situação extrema em que uma empresa com grandes obras sociais e descritivos relatórios qualitativos receberia a nota mínima.

5) Não publicidade dos critérios e julgamentos: uma vez que era divulgado apenas o resultado binário (certificada/não certificada), o processo era pouco esclarecedor a respeito do que deveria ser melhorado, sendo pouco eficaz em termos de aprendizagem institucional. Pelos mesmos motivos, outra dificuldade é o que deveria ser divulgado, pouco contribuindo com a elevação da qualidade e a transparência, e diminuindo o potencial de incentivar a elaboração de balanços sociais pelas empresas.

Dos cinco fatores apontados, os dois primeiros são inerentes aos instrumentos disponíveis e utilizados pela certificação; portanto estão fora do controle do processo. Os três últimos referem-se ao processo em si, e podem ser melhorados a ponto de considerar os dois primeiros na avaliação, atribuindo, por exemplo, maior importância à certificação dos relatórios sociais por auditores independentes. Todos estes cinco fatores poderiam ser objetos de futuras pesquisas, em outros processos de certificação dentro e fora do Brasil. 
Artigo recebido em 30.05.2007. Aprovado em 24.11.2008.

\section{NOTAS}

\footnotetext{
${ }^{1}$ Este artigo não trata de Contabilidade Social. O termo causaria confusão uma vez que tem sido utilizado para definir o conjunto de indicadores extraídos do sistema de registros contábil-estatísticos dos eventos econômicos ou contas nacionais (Filellini, A. (1994). Contabilidade social: resumo da teoria, exercício programados (2a ed., p. 21). São Paulo: Editora Atlas; Paulani, L., \& Braga, M. (2001). A nova contabilidade social. Rio de Janeiro: Saraiva), uma complexa matriz de dados econômicos e monetários conhecida como Social Accounting Matrix [SAM] (para uma revisão sobre o assunto no Brasil ver Lenzen, M., \& Schaeffer, R. (2004). Environmental and social accounting for Brazil. Environmental and Resource Economics, 27(2), 201). Optou-se pela adoção do acrônimo Corporate Social Accounting [CSA] ou Contabilidade Social Corporativa por verificarmos que mais condiz com os objetivos deste estudo.

${ }^{2}$ Comitee on Social Measurement of American Institute of Certified Public Accountants. (1977). The measurement of corporate social performance. New York: Author.

${ }^{3}$ Este efeito é conhecido como externalidade, definida como a perda de bem-estar causada por um agente econômico a outro, sem a devida compensação (Pearce, D. W., \& Turner, R. K. (1990). Economic of natural resources and the environment (p. 61). Baltimore. UK: The Johns Hopkins University Press.

${ }^{4}$ Instituto de Pesquisas Contábeis, Atuarias e Financeiras [FIPECAFI].
}

\section{REFERENCIAS BIBLIOGRÁFICAS}

Adams, C. (2002). Internal organisational factors influencing corporate social and ethical reporting: beyond theorising. Accounting, Auditing \& Accountability Journal, 15(2), 223.

Alexander, M. (1974). Why corporate social accounting? Business Quarterly pre-1986, 39(4), 31.

Alzola, M. (2008). Character and environment: the status of virtues in organizations. Journal of Business Ethics, 78(3), 343-357.

Anonymous. (2005). KPMG survey analyzes CR reporting across the globe. Corporate Responsibility Management, 2(2), 12-13.

Baroudi, J., \& Orlikowsky, W. (1989). The problem of statistical power in MIS research. MIS Quarterly, 13(1), 87-106.

Benbasat, I., Goldstein, D., \& Mead, M. (1987). The case research strategy in studies of information systems. MIS Quarterly, 11(3), 369-386.

Boger, G. (2006). Gestão ambiental e responsabilidade social: um estudo de caso na empresa Dpaschoal filial Uruguaiana. Recuperado em 17 novembro, 2006, de http://br.monografias.com/trabalhos/gestao-ambiental/gestao-ambiental.shtml

Boschi, A. (2003). Balanço social: a contribuição da contabilidade na evidenciação das ações sociais das empresas do Rio Grande do Sul. Dissertação de mestrado, Universidade do Vale dos Sinos, Ciências Contábeis, São Leopoldo, Rio Grande do Sul, Brasil.

Botosan, C., \& Plumlee, M. (2002). A re-examination of disclosure level and the expected cost of equity capital. Journal of Accounting Research, 40(1), 21-40.

Bufoni, A., \& Ferreira, A. (2006). A assimetria informacional do risco ambiental nas demonstrações financeiras: um estudo comparativo Brasil X EUA. Pensar Contábil, 8(31), 20-26. 
Bufoni, A., Ferreira, A., \& Muniz, N. (2007). Utilização do modelo ISAR/UNCTAD: uma análise comparativa. Pensar Contábil, 9(35), 27-34.

Carpes, A. (2004). Um estudo exploratório sobre as práticas utilizadas por empresas brasileiras para evidenciar os investimentos sociais e ambientais. Dissertação de mestrado, Universidade do Vale dos Sinos, Ciências Contábeis, São Leopoldo, Rio Grande do Sul, Brasil.

Carvalho, F., \& Siqueira, J. (2005, outubro). Regulamentações brasileiras do balanço social. Anais do Congresso USP, São Paulo, SP, Brasil, 6.

Cauthorn, T. (1977). Whatever happened to social accountants? Management Accounting, 58(10), 5560.

Cerin, P. (2002). Characteristics of environmental reporters on the OM stockholm exchange. Business Strategy and the Environmental, 11(5), 298-311.

Clifford, S. (2005). So many standards to follow, so little payoff. Inc Magazine, 27(5), 12-13.

Conselho Regional de Contabilidade do Estado do Rio de Janeiro. (2007). Empresa cidadã: comissão divulga regulamento. Recuperado em 11 novembro, 2007, de http://www.crc.org.br/empresa_cidada/emp_cidada.asp.

Consultoria JP Verithas. (2006). SA 8000 - NBR 16001. Recuperado em 17 novembro, 2006, de http://www.jpveritas.com.br/consultoria /sa8000.htm. Último acesso: 17/11/06.

Costa, A., Filho (2002). Um estudo dos balanços sociais dos bancos no Brasil. Dissertação de mestrado, Universidade de Brasília, Brasília, DF, Brasil.

Darnall, N., \& Carmin, J. (2005). Greener or cleaner? The signaling accuracy of U.S. voluntary environmental programs. Policy Sciences, 38(2), 71-90.

David, A. (2003). Balanço social: uma análise das informações evidenciadas pelas empresas. Dissertação de mestrado, Universidade do Vale dos Sinos, Ciências Contábeis, São Leopoldo, RS, Brasil.

Dentchev, N. A. (2004). Corporate social performance as a business strategy. Journal of Business Ethics, 55(4), 397-412.

Detomasi, D. A. (2008). The political roots of corporate social responsibility. Journal of Business Ethics, 82(4), 807-819.

Dias, L. (2006). Análise da utilização dos indicadores do Global Reporting Initiative (GRI) nos relatórios sociais em empresas brasileiras. Dissertação de mestrado, Universidade Federal do Rio de Janeiro, Rio de Janeiro, RJ, Brasil.

European Commission. (2001a, July 18). Corporate responsibility: commission opens public debate. European Reports. Brussels: EU Commission.

European Commission. (2001b, June). Green paper: promoting a european framework for corporate social responsibility. European Reports. Brussels: EU Commission.

Giacalone, R., Paul, K., \& Jurkiewicz, C. L. (2005). A preliminary investigation into the role of positive psychology in consumer sensitivity to corporate social performance. Journal of Business Ethics, 58(4), 295-305.

Gilley, K. M., Worrell, D. L., Davidson, W., \& El-Jelly, A. (2000). Corporate environmental initiatives and anticipated firm performance: the differential effects of process-driven versus product-driven greening initiatives. Journal of Management, 26(6), 1199-1216. 
Gobbels, M., \& Jonker, J. (2003). AA1000 and SA8000 compared: a systematic comparison of contemporary accountability standards. Managerial Auditing Journal, 18(1), 54-58.

Gond, J., Herrbach, O. (2006). Social reporting as an organisational learning tool? A theoretical framework. Journal of Business Ethics, 65(4), 359-371.

Gray, R. (2001). Thirty years of social accounting, auditing and reporting: what (if anything) have we learnt? Business Ethics: A European Review. Blackwell Publishers Ltd., 10(1), 9-15.

Gray, R., Kouhy, R., \& Lavers, S. (1995). Corporate social and environmental reporting: a review of the literature and a longitudinal study of UK disclosure. Accounting, Auditing \& Accountability Journal, 8(2), 47-77.

Hendriksen, E., Breda, M. van. (2001). Teoria da contabilidade. São Paulo: Atlas.

Institute of Social and Ethical Accountability. (1999). Accountability 1000 (AA1000): a foundation standard in social and ethical accounting, auditing and reporting. Overview of Standard and its Applications. London, UK: Author.

Instituto Brasileiro de Análises Sociais e Econômicas. (2009). Balanço Social - Mensagem do Betinho. Recuperado em 24 maio, 2009, de http://www.balancosocial.org.br/cgi/ cgilua.exe/sys/start.htm?sid=32

International Labour Organization. (1998). Declaration on fundamental principles and rights at work. International Labour Organization, Geneva. Recuperado em 17 novembro, 2006, de http://www.ilo.org/wcmsp5/groups/public/---ed_norm/--- /publication declaration/ documents/wcms_095895.pdf

Klassen, R., \& McLaughlin, C. (1996). The impact of environmental management on firm performance. Management Science, 42(8), 1199-1214.

Kok, P., Wiele, T., McKenna, R., \& Brown, A. (2001). A corporate social responsibility audit within a quality management framework. Journal of Business Ethics, 31(4), 285-297.

Kolk, A. (2003). Trends in sustainability reporting by the fortune global 250. Business Strategy and the Environment, 12(5), 279-291.

Kroetz, C. (2000). Balanço social: teoria e prática. São Paulo: Atlas.

Laan, G., \& Witteloostuijn, A. V. (2007). Corporate social and financial performance: an extended stakeholder theory, and empirical test with accounting measures. Journal of Business Ethics, 79(3), 299-310.

Laufer, W. (2003). Social accountability and corporate greenwashing. Journal of Business Ethics, 43(3), 253-261.

Leipziger, D. (2001). SA8000: the definitive guide to the new social standard. London: Financial Times-Prentice Hall.

Lima, D., \& Viegas, W. (2002). Tratamento contábil e evidenciação das externalidades ecológicas. Revista Contabilidade e Finanças, (30), 46-53.

Magrini, A. (1999). [Apostila do curso de gestão ambiental]. Rio de Janeiro: PPE/COPPE/UFRJ.

Miles, M., \& Covin, J. G. (2000). Environmental marketing: a source of reputational, competitive, and financial advantage. Journal of Business Ethics, 23(3), 299-311.

Miles, M., \& Munilla, L. (2004). The potential impact of social accountability certification on marketing: a short note. Journal of Business Ethics, 50(1), 1-11. 
Miller, P. (January, 2001). Will you adopt quality finance reporting? Strategic Finance, 82(7), 50-56.

National Minority Supplier Development Council. (2005). 2005 Annual Report. Recuperado em 25 maio, 2007, de http://www.nmsdc.org/infocenter/Annual\%20Report05.pdf

O'Dwyer, B. (2001). The legitimacy of accountants' participation in social and ethical accounting, auditing and reporting. Business Ethics: A European Review, 10(1), 27-39.

Owen, D., \& Swift, T. (2001). Introducing social accounting, reporting and auditing: beyond the rhetoric? Business Ethics: A European Review, 10(1), 4-8.

Pinto, A. (2003). Balanço social: avaliação de informações fornecidas por empresas industriais situadas no Estado de Santa Catarina. Dissertação de mestrado, Universidade de São Paulo, Controladoria e Contabilidade, São Paulo, SP, Brasil.

Ribeiro, M., Santos, A. (2002, November). Disclosure of democratization of economic development through the social balance sheet. Proceedings of the Asian Pacific Conference on International Accounting Issues, Los Angeles, EUA, 14.

Rosthorn, J. (2000). Business ethics auditing - More than a stakeholder's toy. Journal of Business Ethics, 27(1-2), 9-19.

Roth, H. (1982). A role for small business in the social accounting area. Journal of Small Business Management, 20(1), 27-31.

Solomon, A. (2000). Could corporate environmental reporting shadow financial reporting? Accounting Forum, 24(1), 30-55.

Stevens, J. P. (1980). Power of multivariate analysis of variance test. Psychological Bulletin, 88(3), 728-737.

Tachizawa, T. (2002). Gestão ambiental e responsabilidade social: estratégias de negócios focados na realidade brasileira. São Paulo: Atlas.

Taylor, T. C. (1976). The illusions of social accounting. The CPA Journal (pre-1986), 46, 24-28.

Tilt, C. (1994). The influence of external pressure groups on corporate social disclosure: some empirical evidence. Accounting, Auditing \& Accountability Journal, 7(4), 47-72.

United Nations Conference on Trade and Development. (2003). Disclosure of the impact of corporations on society: current trends and issues (Report by the UNCTAD secretariat), Geneva, Trade and development board, commission on investment, technology and related financial issues intergovernmental working group of experts on international standards of accounting and reporting. Recuperado em 17 novembro, 2006, de http://www.unctad.org/en/docs//c2isar20_en.pdf

Williams, G., \& Phillips, T. (1994). Cleaning up our act: accounting for environmental liabilities. Management Accounting, 75(8), 30-33.

Yin, R. (1994). Case study research, design and methods (2nd ed.). Beverly Hills, California: Sage Publications.

Zietsma, Z., Winn, M., Branzei, O., \& Vertinsky, I. (2002). The war of the woods: facilitators and impediments of organizational learning processes. British Journal of Management, 13(S2), S61-S74. 


\section{ANEXO 1}

\section{Empresas Certificadas de 2003 à 2007}

\begin{tabular}{|c|c|c|}
\hline Certificadas em 2007 & Certificadas em 2006 & Certificadas em 2005 \\
\hline Petrobrás & Ampla & Itau \\
\hline COPEL & COPEL & COPEL \\
\hline Ampla & Ipiranga & LIGHT \\
\hline Caixa Econômica Federal & Acesita & PETROBRAS \\
\hline Coelba Grupo Neoenergia & Camargo Corrêa & Sercomtel Telecomunicações \\
\hline Marisol & PETROBRAS & Furnas - Centrais Elétricas S.A. \\
\hline Serasa & Furnas - Centrais Elétricas S.A. & Ampla \\
\hline Sadia & Serasa & Caixa Econômica Federal \\
\hline Usiminas & Companhia Siderúrgica Nacional & Sercomtel Celular \\
\hline Acesita & Eletronuclear & ACESITA \\
\hline Itau & Itau & Petroflex \\
\hline Bradesco & Caixa Econômica Federal & EMBRAER \\
\hline Eletrobrás & CEDAE & Companhia Siderúrgica Nacional \\
\hline Camargo Correa & Santander Banespa & Banco do Brasil \\
\hline CVRD & Lamsa & CEDAE \\
\hline Instituto Invepar & Banco do Brasil & Tele Norte Leste Participações S.A. \\
\hline Banco do Brasil & Eletrobras & Cia Paulista de Trens Metrop. - CPTM \\
\hline Furnas Centrais Elétricas & Petroflex & CVRD \\
\hline Gerdau & Souza Cruz & \\
\hline Cia Distribuidora de Gás & CEG & Certificadas em 2004 \\
\hline Embraer & CVRD & Sul América Seguros \\
\hline Eletrobrás Termonuclear & Embrapa $^{\dagger}$ & Petroflex Indústria e Comércio \\
\hline BB Seguros & & Furnas - Centrais Elétricas \\
\hline Petroflex & Certificadas em 2003 & Shell do Brasil \\
\hline Sul América Seguros & PETROBRAS & PETROBRAS \\
\hline Geraldo J. Coan e Cia Ltda * & Petroflex Indústria e Comércio S.A. & EL PASO \\
\hline Unimed * & Shell do Brasil & Companhia Vale do Rio Doce \\
\hline Indústrias Granfino * & Companhia Vale do Rio Doce & $\mathrm{CSN}$ \\
\hline Embrapa * & CEDAE & LIGHT \\
\hline Escritório de Arrecadação - ECAD * & Sul América Seguros & CEDAE \\
\hline CECREMEF * & Furnas - Centrais Elétricas & ELETRONUCLEAR \\
\hline Real Grandeza * & LIGHT - Serviços de Eletricidade & \\
\hline Associação Franciscana * & & \\
\hline
\end{tabular}

